\title{
O reconhecimento da autoridade ancilar da FCC pela Suprema Corte norte-americana: convergência com a aplicação da teoria dos poderes implícitos no direito brasileiro
}

Supreme Court recognition of the FCC ancillary authority: Comparison with Brazilian courts interpretation on the doctrine of implied powers

Submetido(submitted): 3 de fevereiro de 2013

Parecer(revised): 10 de março de 2013

Aceito(accepted): $1^{\circ}$ de abril de 2013

Rogerio Assis Carmo*

Informe setorial

Atualizado até janeiro de 2013

\section{RESUMO}

Propósito - Este informe compara os institutos da autoridade ancilar e dos poderes implícitos no desenvolvimento de teoria sobre competências administrativas das agências reguladoras brasileiras.

Metodologia/abordagem/design - Descreveu-se o delineamento da competência ancilar da FCC a partir de julgados da Suprema Corte dos Estados Unidos e da Corte de Apelações do Distrito de Colúmbia. Apresentaram-se lições doutrinárias e manifestações de Ministros do Supremo Tribunal Federal brasileiro sobre o reconhecimento de poderes implícitos ao necessário cumprimento de deveres legais.

Resultados - Demonstrou-se a confluência dessas duas vertentes teóricas para o reconhecimento de competências não diretamente expressas das agências reguladoras.

Implicações práticas - $\mathrm{O}$ trabalho contribui para o reconhecimento de competências da agência reguladora das telecomunicações brasileira que, embora não estejam dispostas expressamente, emergem como uma imperiosidade para o cumprimento de responsabilidades diretamente dadas por lei àquela autarquia.

Originalidade/relevância do texto - $\mathrm{O}$ artigo apresenta instituto jurídico corrente na tradição norte-americana cuja aplicação à área de telecomunicações brasileira

\footnotetext{
*Auditor Federal de Controle Externo do Tribunal de Contas da União (TCU). Graduado em Direito e Mestrando em Regulação na Universidade de Brasília. Contato: rogerioac@tcu.gov.br.
} 
ainda não está sedimentada, não obstante a sua compatibilidade com conceitos já aceitos no direito pátrio.

Palavras-chave: regulação; autoridade ancilar; poderes implícitos; Brasil; Estados Unidos da América.

\begin{abstract}
Purpose - This update proposes the comparison between ancillary authority and implied power doctrine applied on Brazilian administrative agencies competences.

Methodology/approach/design - It describes the design of FCC's ancillary jurisdiction based on US Supreme Court and Court of Appeals for the District of Columbia decisions. It also presents Brazilian doctrine and Federal Supreme Court justices' opinions on the recognition of implied powers necessary to fulfill legal duties.

Findings - This study found confluence between those two theoretical sources ancillary authority and implied power doctrine - towards the recognition of not directly expressed administrative agencies regulatory authority.

Practical implications - This update contributes to the recognition of Brazilian telecommunications regulatory agency's powers which, although not expressly disposed, emerge as an imperative to fulfill responsibilities given directly by legal statutes.

Originality/value - This study presents the concept of ancillary authority current in the American tradition that, although not yet confirmed under Brazilian telecommunications law, it is commensurable to concepts already accepted by the Brazilian Supreme Court in accord with the implied power doctrine.
\end{abstract}

Keywords: regulation; ancillary authority; implied power doctrine; Brazil; United States of America.

\title{
1. Introdução
}

Em campos sempre em transformação provocada por rápidas mudanças tecnológicas e mercadológicas, tal como o de telecomunicações, podem surgir questões sobre as competências das agências reguladoras em setores e atividades novas e não previstas expressamente nas precedentes normas de 
criação e de atribuições dessas entidades. Há precedentes da Suprema Corte dos Estados Unidos que reconheceram uma competência da Federal Communications Commission - FCC para regular setores e atividades não direta e expressamente mencionadas na sua lei de criação e de disciplina de seus poderes e atuação: o Communications Act de 1934. Essa autoridade foi reconhecida como meio necessário e ancilar ao cumprimento das responsabilidades atribuídas à Comissão por esse mesmo diploma.

Encontra ressonância no direito brasileiro a noção de competência cujo exercício requer o reconhecimento de poderes implicitamente exigidos para a realização de deveres administrativos. Este artigo enfrenta precisamente a questão da similitude dos institutos da autoridade ancilar desenvolvida no direito norte-americano, e dos poderes implícitos presente na literatura jurídica brasileira, ciente da afirmação doutrinária corrente em estudos de direito constitucional brasileiro, que correlacionam a doutrina dos poderes implícitos à doutrina dos inherent powers da jurisprudência da Suprema Corte dos Estados Unidos da América.

\section{A emergência da noção de autoridade ancilar da FCC em casos julgados pela Suprema Corte dos Estados Unidos sobre a atividade de televisão a cabo}

A noção de autoridade ancilar é desenvolvida nos seguintes julgados da Suprema Corte estadunidense: United States v. Southwestern Cable Co. ${ }^{1}$; United States v. Midwest Video Corp. ${ }^{2}$; e Federal Communications Commission v. Midwest Video Corp. ${ }^{3}$

Nesses três casos, tratou-se de regras da FCC para, sob os ditames do Communications Act de 1934, regular atividade inicialmente conhecida como Televisão por Antena Comunitária (Community Antenna Television CATV) e que, posteriormente, com o desenvolvimento de novas funcionalidades, passou a ser designada pelo termo televisão a cabo (cable television).

\footnotetext{
1392 U.S. 157 (1968).

2406 U.S. 649 (1972).

${ }^{3} 440$ U.S. 589 (1979).
} 
O Communications Act de 1934 precedeu o advento das CATV e das televisões a cabo. Assim, como era de se supor, aquele ato originalmente não contemplou regras expressas para a regulação desse meio de telecomunicação. ${ }^{4}$ Dita situação permanecia à época dos casos ora apresentados, consoante denotam as manifestações dos relatores ${ }^{5}$ para os respectivos acórdãos.

Os sistemas de CATV recebiam sinais das televisões abertas e os amplificavam para retransmissão via cabo ou microondas. Esses sistemas CATV não remuneravam as produtoras ou distribuidoras de programas das televisões abertas e, em geral, cobravam contraprestação pecuniária de seus clientes. Nos primórdios e em geral, as CATV não produziam programação própria.

Os sistemas CATV foram inicialmente estabelecidos sem fins comerciais, em 1949. Porém, já em 1950 foi estabelecido o primeiro sistema comercial. A partir daí, o setor passou por um crescimento explosivo. Ao final dos anos 1950, havia 550 sistemas servindo 2 milhões de pessoas. Em 1965, eram 1.857 sistemas em operação, acrescidos de 758 já licenciados e 938 pedidos de licença. Outrossim, em 1959, somente 50 sistemas operavam em microondas e seus sinais alcançavam no máximo 300 milhas. Em 1964, eram 250 os que usavam microondas e os sinais ultrapassavam 665 milhas.

Os sistemas CATV cumpriam uma ou ambas das seguintes funções: a) supriam a recepção de sinais das televisões abertas em locais onde isso não era possível por outro modo; b) transmitiam sinais de estações distantes para antenas locais. À medida em que aumentava o número e o escopo dos sistemas CATV, a principal função passou a ser a importação de sinais de estações distantes. Assim, embora originalmente servissem como auxiliares

\footnotetext{
${ }^{4}$ Redação original, disponível no http://www.criminalgovernment.com/docs/61StatL 101/ComAct34.html, acesso em 19/1/2013.

${ }^{5}$ Nas transcrições de dispositivos do Communications Act de 1934 incorporadas a este trabalho, indica-se a correspondência entre a redação reproduzida nos acórdãos com a redação original ou com a atual. Na redação original, não há referências às expressões cable television ou cable communications. Essas expressões constam da versão atual, disponível no http://transition.fcc.gov/Reports/1934new.pdf, acesso em 20/1/2013, a qual, inclusive conta com um título inteiro sobre o assunto (Title VI Cable Communications). Esse título foi acrescentado pelo Cable Communications Act de 1984.
} 
da distribuição local para áreas isoladas e terrenos adversos à recepção dos sinais abertos, os sistemas CATV se espalharam por áreas metropolitanas. Aproximavam-se, então, de se tornarem um novo sistema de comunicações de âmbito nacional, no qual os sinais de televisão poderiam ser transmitidos a áreas metropolitanas por todo o país.

A predisposição da FCC para regular as CATVs sofreu modificações ao longo dos anos de expansão do serviço.

Em 1959, entendeu a FCC que as CATVs não seriam radidifusores (broadcasters), como as televisões abertas, e nem detentores de infraestrutura essencial (common carriers), portanto, não se enquadravam entre as atividades então expressamente disciplinadas no Communications Act de 1934 e sujeitas à sua regulação. Considerou também que, não obstante os presumidos impactos das CATVs sobre as televisões abertas, não seria possível precisar antecipadamente os efeitos disso. Sugeriu então que o assunto fosse disciplinado pelo Congresso, o que não se sucedeu malgrado tentativa de alteração do Communications Act de 1934.

Em 1962, reavaliando a significância das CATVs perante suas competências regulatórias, a FCC admitiu que a probabilidade de efeitos adversos da competição com as CATVs sobre as audiências e as receitas das televisões abertas locais tornara-se substancial e já não mais poderia ser ignorada. A agência impôs, então, duas regras: a) as CATVs deveriam retransmitir os sinais de todas as estações localizadas nas áreas para as quais transmitiam (carriage rule); b) as CATVs não poderiam duplicar a programação dessas televisões locais no período dos 15 dias anteriores e posteriores à transmissão local (nonduplication rule).

\subsection{O caso United States v. Southwestern Cable Co., de 1968}

Em seguida a audiências realizadas em 1965 e após sustentar que o Communications Act de 1934 lhe conferia autoridade regulatória sobre todas as formas de CATV, fossem por microondas ou por cabos, a FCC proibiu que as CATVs levassem sinais de estações distantes para os 100 maiores mercados de televisão aberta. Exceções haveria para os casos de serviços já em operação antes de 15/2/1966 ou quando a FCC considerasse que a transmissão seria consistente com o interesse público, particularmente com o estabelecimento e a manutenção do serviço de televisão aberta na 
área a ser servida por uma CATV. Na ocasião, a FCC criou procedimentos sumários para a aplicação dessas regras.

\subsubsection{O litígio}

Pouco depois de editada a regra de restrição de sinais de longa distância via CATV para os grandes mercados de televisão, a Midwest Television representou à FCC contra a transmissão da Southwestern Cable Co. de sinais de Los Angeles para San Diego.

Como San Diego, à época, era o $54^{\circ}$ mercado de televisão nos Estados Unidos, a FCC, entendendo que não haveria como reconhecer interesse público a justificar a questionada importação de sinais, restringiu a possibilidade de transmissão de CATV pela Southwestern Cable Co. às áreas onde ela já operasse esse serviço até 15/2/1966, o que excluiria a área de San Diego.

Levado o caso à Corte de Apelações do $9^{\circ}$ Circuito, esta sustentou que, à luz do Communications Act de 1934, faltava à FCC autoridade para implementar tal restrição.

\subsubsection{A posição da Suprema Corte}

O ponto a ser destacado, para as finalidades deste trabalho, reside nas análises e respostas da Suprema Corte a questionamento sobre se, sob o Communications Act de 1934, a FCC detinha competência para regular os serviços de CATV.

Argumentou-se que a FCC teria imposto restrições às CATVs com base em item das disposições gerais do Communications Act de 1934 (Title IGeneral Provisions) ${ }^{6}$, que apenas aponta quais as formas de telecomunicação que estariam sujeitas às disposições específicas contidas nos capítulos sobre detentores de infraestrutura essencial (Title II Common carriers) ou radiodifusão (Title III - Provisions relating to radio).

\footnotetext{
6"The provisions of this act shall apply to all interstate and foreign communication by wire or radio and all interstate and foreign transmission of energy by radio, which originates and/or is received within the United States, and to all persons engaged within the United States in such communication or such transmission of energy by radio, and to the licensing and regulating of all radio stations as hereinafter provided." (Transcrição da redação original do estatuto. Na versão atual, essa parte do dispositivo permanece igual).
}

Revista de Direito, Estado e Telecomunicações, v. 5, n. 1, p. 195-226 (2013)

DOI: https://doi.org/10.26512/1str.v5i1.21568 
Assim, argumentando-se que as características das CATVs, como reconhecido pela própria FCC, em 1959, não se enquadravam perfeitamente nas categorias de common carriers ou de broadcasters, então expressamente mencionadas no Communications Act de 1934 como aquelas sujeitas à regulação da FCC, elas não seriam alcançadas por este estatuto e, portanto, não poderiam ser reguladas pela $\mathrm{FCC}^{7}$

A Suprema Corte, porém, lembrou que a competência da FCC para regular os serviços de radiodifusão e outras formas de telecomunicações derivava do Communications Act de 1934, que, conforme disposição explícita, deveria ser aplicado a todas as telecomunicações interestaduais ${ }^{8} \mathrm{e}$ internacionais. Anotou também que as responsabilidades que o diploma atribuiu à FCC não seriam mais estreitas do que o campo de aplicação de suas regras, uma vez que à Comissão caberia trabalhar para tornar acessível a todo o povo dos Estados Unidos telecomunicações velozes, eficientes e de escala nacional e mundial. ${ }^{9}$

${ }^{7}$ Na redação original, o Communications Act de 1934 apresentava-se dividido nos
seguintes títulos: Title I - General Provisions; Title II - Common Carriers; Title III
- Provisions relating to radio; Title IV-Procedural and administrative provisions;
Title V - Penal Provisions - Forfeitures; Title VI - Miscellaneous Provisions). Na
versão atual, como já mencionado, foi acrescentado mais um título, implicando
renumeração dos tópicos para Title VI - Cable Communications e Title VII -
Miscellaneous Provisions.
${ }^{8}$ Como no caso analisado os sinais eram transmitidos dentro de um mesmo estado,
foram lançadas dúvidas sobre se isso caracterizaria telecomunicação interestadual. A
Suprema Corte esclareceu que a programação das televisões consistia, em grande
parte, em conteúdos originados de vários estados e distribuídos nacionalmente, de
modo que caracterizar a questionada atividade da Southwestern como intraestadual
seria desconsiderar característica essencial da indústria de televisão.
"For the purpose of regulating interstate and foreign commerce in
communication by wire and radio so as to make available, so far as possible, to all
the people of the United States a rapid, efficient, Nation-wide, and world-wide wire
and radio communication service with adequate facilities at reasonable charges,
for the purpose of the national defense, and for the purpose of securing a more
effective execution of this policy by centralizing authority heretofore granted by law
to several agencies and by granting additional authority with respect to interstate
and foreign commerce in wire and radio communication, there is hereby created a
commission to be known as the "Federal Communications Commission", which
shall be constituted as hereinafter provided, and which shall execute and enforce
the provisions of this Act." (Transcrição da versão original. Versão atual com
modificações). 
Destacou, então, a Suprema Corte que nada no texto ou na história da elaboração do Communications Act de 1934 limitava a competência da FCC àquelas atividades e modalidades de telecomunicação nele especificamente descritas e, ademais, os sistemas CATV estariam abarcados nas amplas definições de telecomunicações por fio ou por radiodifusão nele estabelecidas. $^{10}$

Para a Suprema Corte, conforme manifestações na mensagem do Presidente Roosevelt que encaminhou a proposta de legislação e nos relatórios das comissões que a analisaram no Congresso, pela edição do Communications Act de 1934, buscou-se conferir à FCC uma autoridade unificada e abrangente sobre todas as formas de telecomunicações, de maneira a manter sobre apropriado controle administrativo os dinâmicos aspectos das telecomunicações. Assim, embora, à época, não se pudesse antever o rápido crescimento dos sistemas de CATV, o Communications Act de 1934 conferiu aos processos regulatórios flexibilidade suficiente para que se ajustassem às rápidas evoluções do setor.

Também entendeu a Suprema Corte que, para o cumprimento de responsabilidades da Comissão tocantes à equitativa distribuição dos serviços de radiodifusão, nos termos do Communications Act de $1934^{11}$, e ao seu papel no desenvolvimento e na preservação de sistemas locais de

10"DEFINITIONS (...) For the purposes of this Act, unless the context otherwise requires- (a) "Wire communication" or "communication by wire" means the transmission of writing, signs, signals, pictures, and sounds of all kinds by aid of wire, cable, or other like connection between the points of origin and reception of such transmission, including all instrumentalities, facilities, apparatus, and services (among other things, the receipt, forwarding, and delivery of communications) incidental to such transmission. (b) "Radio communication" or "communication by radio" means the transmission by radio of writing, signs, signals, pictures, and sounds of all kinds, including all instrumentalities, facilities, apparatus, and services (among other things, the receipt, forwarding, and delivery of communications) incidental to such transmission." (Transcrições da versão orginal. Versão atual com modificações).

11'In considering applications for licenses, and modifications and renewals Communications Act of 1934 thereof, when and insofar as there is demand for the same, the Commission shall make such distribution of licenses, frequencies, hours of operation, and of power among the several States and communities as to provide a fair, efficient, and equitable distribution of radio service to each of the same." (Transcrição da versão atual. Versão original não corresponde ao texto reproduzido no acórdão).

Revista de Direito, Estado e Telecomunicações, v. 5, n. 1, p. 195-226 (2013)

DOI: https://doi.org/10.26512/1str.v5i1.21568 
radiodifusão, seria imperativo reconhecer a autoridade regulatória da FCC sobre as CATVs, visto que a importação de sinais de televisões distantes poderia desestimular a atividade de radiodifusão local.

A Suprema Corte concluiu que a autoridade da FCC sobre todas as telecomunicações interestaduais por fio ou rádio, conferida nos termos do Communications Act de 1934, permitia que ela regulasse os sistemas de CATV, mas enfatizou que essa autoridade deveria restringir-se ao que fosse razoavelmente ancilar ao efetivo atendimento das responsabilidades da Comissão para regular a radiodifusão. ${ }^{12}$

\subsection{O caso United States v. Midwest Video Corp., de 1972}

Esse caso também versou sobre a competência da FCC para regular serviços de Televisão por Antena Comunitária (Community Antenna Television - CATV) e seguiu a orientação do já mencionado caso precedente, United States v. Southwestern Cable Co., de 1968, quando a Suprema Corte reconheceu uma competência regulatória da FFC sobre tais serviços, desde que restrita ao razoavelmente ancilar ao cumprimento de seus deveres legais.

$\mathrm{Na}$ ocasião deste julgado, foi mencionado o contínuo crescimento do número de sistemas de CATV, que já somavam 2.678 em operação, 1.916 licenciados embora inoperantes e 2.804 pedidos de licenciamento. Foi também destacado que a evolução dos sistemas a cabo, já contando com capacidade de múltiplos canais, permitiria a oferta de novos e variados serviços, tais como fax, correio eletrônico e transmissão de dados (facsimile reproductions of documents, eletronic mail delivery, and information retrieval). Anotou-se, então, que, por essas razões, a FCC, ainda no ano de 1972, mas posteriormente à edição da norma avaliada nesse caso, passara a adotar o termo cable television em lugar de CATV.

Desta feita, a norma em questão, além de reforçar exigência para que as CATVs operassem na transmissão de distribuição de conteúdos locais, visou impelir essas CATVs a atuarem também como produtoras de novos

${ }^{12}(. .$.$) the authority (...) is restricted to that reasonably ancillary to the effective$ performance of the Commission's various responsibilities for the regulation of television broadcasting. (Decisão da Suprema Corte no caso United States v. Southwestern Cable Co.) 
programas, na medida em que se passou a exigir que elas estivessem equipadas para a criação de novos programas (program-origination rule).

\subsubsection{O litígio}

Logo após o julgamento do caso United States v. Southwestern Cable Co., de 1968, a FCC iniciou procedimentos para explorar alternativas de como as CATVs poderiam melhor atender ao público, especialmente quanto a atuarem como veículos para a autoexpressão de comunidades, mediante a produção de programas locais.

Ao final do processo, a Comissão, em 24/10/1969, editou uma regra, aplicável às CATVs com 3.500 ou mais assinantes, que as obrigava a operar como distribuidoras de conteúdos locais e a possuírem equipamentos para a produção de programas locais, sob pena de não poderem transmitir os sinais das televisões abertas.

Para a FCC, essa regra estaria afinada com o propósito primordial de sua criação de, conforme ditames do Communications Act de 1934, tornar acessível a todo o povo americano os serviços de comunicação por rádio ou cabo, além de cumprir outros objetivos também previstos no referido estatuto, de incentivar o uso mais efetivo do rádio no interesse público e promover a distribuição equitativa dos serviços de televisão entre os vários estados e comunidades.

Mediante provocação da Midwest Video Corp., a Corte de Apelações para o Oitavo Circuito anulou a regra, por entender que faltava à FCC a competência para impô-la, visto que as disposições estariam muito além do limite dado pelo critério do que seria razoavelmente ancilar às responsabilidades e objetivos de criação da Comissão.

\subsubsection{A posição da Suprema Corte}

A Suprema Corte, por maioria ${ }^{13}$, desfez a decisão da Corte de Apelação, por entender que a chamada program-originating rule se comportava nos limites para o exercício de uma autoridade que, embora não expressa, seria

\footnotetext{
${ }^{13}$ Maioria formada por Brennan, J., relator para o acórdão, seguido por White, Marshall e Blackmun, J.J. Com a posição da maioria, embora por fundamentos diversos, concordou Burger, C.J. A dissidência partiu de Douglas, no que foi acompanhado por Stewart, Powell e Rehnquist, J.J.
}

Revista de Direito, Estado e Telecomunicações, v. 5, n. 1, p. 195-226 (2013)

DOI: https://doi.org/10.26512/lstr.v5i1.21568 
razoavelmente ancilar ao efetivo desempenho das várias responsabilidades sobre a regulação da radiodifusão.

Essa posição pautou-se em entendimento de que a competência da FCC para regular as CATVs se legitimava não apenas para a proteção, como também para a promoção dos objetivos pelos quais lhe fora conferida autoridade regulatória sobre toda a radiodifusão, aí incluído o fortalecimento da programação local e a diversificação de programas e tipos de serviço.

\subsection{O caso United States v. Midwest Video Corp., de 1979}

Como já anotado, à medida em que se ampliavam os potenciais usos para os serviços das então conhecidas CATVs, a FCC passou a adotar o termo televisão a cabo (cable television), mais abrangente, para fazer referência a essa atividade que já se apresentava como uma nova indústria de telecomunicações.

Em maio de 1976, a FCC editou regra impondo aos sistemas de televisão a cabo com mais de 3.500 assinantes e que transmitiam sinais das televisões abertas a portarem capacidade para, no mínimo, 20 canais e dedicarem de um a quatro desses canais para acesso por terceiros, em especial, por entes de caráter público, instituições educacionais, governos locais ou locadores de acesso (public, educational, local governmental and leased-access users), além de deterem todo o equipamento necessário para esse propósito. Sob essas regras, as televisões a cabo não teriam escolha sobre quem iria usar os canais de acesso dedicados ao público (access channels) nem controle sobre o que por eles seria transmitido. Também foram regulados os valores que poderiam ser cobrados pelos usos desses canais de acesso e de instalações e equipamentos dos operadores de televisão a cabo. ${ }^{14}$

\subsubsection{O litígio}

A FCC entendeu que essas regras imporiam ônus menor do que a regra de geração de programação própria para realizar propósitos legais para os quais foi criada a Comissão, dentre eles os consagrados no caso United

\footnotetext{
${ }^{14}$ Ao conjunto dessas regras designou-se Commission's access, channel capacity, and facility rules.
} 
States v. Midwest Video Corp., de 1972, de aumentar o número de veículos para a auto-expressão das comunidades locais bem como de programas e tipos de serviços para a escolha do público.

Para a Comissão, a oferta dos canais de acesso representaria um bem social e as regras nesse sentido orientavam-se por objetivos que ela deveria perseguir na atividade de regulação da radiodifusão, similarmente àquelas que foram assim reconhecidas pela Suprema Corte nos anteriores casos United States v. Southwestern Cable Co., de 1968, e United States v. Midwest Video Corp, de 1972.

A Midwest Video Corp. insurgiu-se alegando que as exigências de canais de acesso dedicados a usuários especificados pela FCC e sem que as operadoras das televisões a cabo pudessem selecionar esses usuários ou controlar a programação por eles veiculada implicavam considerável grau de subtração da autonomia editorial e a imposição de obrigações tipicamente oponíveis aos detentores de infraestrutura essencial (common carriers), o que seria contrário à expressa exclusão dos radiodifusores da definição de detentores de infraestrutura essencial (common carriers) dada pelo Communications Act de $1934^{15}$. Por essas razões, a empresa alegou que as questionadas regras de acesso configuravam uma ingerência nas operações das televisões a cabo qualitativamente diferente daquelas regras reconhecidas como válidas nos casos United States v. Southwestern Cable Co., de 1968, e United States v. Midwest Video Corp., de 1972.

Para a Comissão, como as regras relacionavam-se ao alcance, em termos razoáveis, dos objetivos para os quais fora fixada a sua autoridade, elas não poderiam ser consideradas como exorbitantes de sua competência apenas por serem identificadas com natureza própria da regras afetas à regulação de common carriers. Para a FCC, o argumento decisivo era de que as adotadas regras promoviam seus objetivos legais.

\footnotetext{
${ }^{15}$ Title I, Sec. 3(h) do Communications Act de 1934: "Common carrier" or "carrier" means any person engaged as a common carrier for hire, in interstate or foreign communication by wire or radio or in interstate or foreign radio transmission of energy, except where reference is made to common carriers not subject to this Act; but a person engaged in radio broadcasting shall not, insofar as such person is so engaged, be deemed a common carrier. (Transcrição da versão original. Versão atual com modificações).
}

Revista de Direito, Estado e Telecomunicações, v. 5, n. 1, p. 195-226 (2013)

DOI: https://doi.org/10.26512/lstr.v5i1.21568 
Quanto aos valores da Primeira Emenda à Constituição norte-americana (First Amendment to the United States Constitution) ${ }^{16}$, para a FCC, no tocante à regulação da radiodifusão e atividades correlatas, eles estariam homenageados pelas medidas que favoreciam a circulação de ideias.

A Corte de Apelações para o Oitavo Circuito invalidou as regras de acesso, capacidade e instalações em comento, entendendo que elas traziam uma afronta a expresso comando legal, vedando a extensão à atividade correlata à dos radiodifusores como, no caso, das televisões a cabo, de tratamento próprio de common carriers.

Isto posto, a Corte concluiu que as regras discutidas no caso United States v. Midwest Video Corp. de 1979, não seriam razoavelmente ancilares à competência da FCC para regular a atividade de radiodifusão. Para a Corte de Apelações, tais regras também significavam graves ofensas à First Amendment.

\subsubsection{A posição da Suprema Corte}

Nesse caso, a decisão da maioria ${ }^{17}$ da Suprema Corte foi por reafimar a decisão da Corte de Apelações, destacando que a chamada autoridade ancilar não seria ilimitada e não poderiam desconsiderar disposições do Communications Act de 1934 que protegiam a liberdade editorial de radiodifusores e, por extensão, também de operadores de televisão a cabo.

A Suprema Corte acolheu o argumento da Midwest Video Corp. de que as regras de acesso aos canais a cabo extrapolavam o campo da competência da FCC reconhecido nos anteriores julgados sobre a atividade das CATVs.

Para a Suprema Corte, diferentemente daquelas outras normas, as regras de acesso traziam uma elisão do controle das operadoras de televisão a cabo sobre o conteúdo da programação que deveriam transmitir, relegando-as, nessas situações, ao status de common carriers.

\footnotetext{
${ }^{16}$ Texto da Primeira Emenda à Constituição norte-americana: "Congress shall make no law respecting an establishment of religion, or prohibiting the free exercise thereof; or abridging the freedom of speech, or of the press; or the right of the people peaceably to assemble, and to petition the Government for a redress of grievances". ${ }^{17}$ Posição majoritária expressa por White, J., com a anuência de Stewart, Blackmun, Powell, e Rehnquist, JJ. A minoria formou-se com Stevens, seguido por Brennan e Marshall, J.J.
} 
Ressaltou a Suprema Corte que, no Communications Act de 1934, havia texto estipulando, de modo inequívoco, que radiodifusores não deveriam ser tratados como common carriers, o que seria consistente com os propósitos do mesmo estatuto, como reconhecido em caso anterior, Columbia Broadcasting System, Inc. v. Democratic National Commitee ${ }^{18}$, de preservar para o radiodifusor licenciado o controle editorial da programação sem interferências da FCC.

Conforme decisão da Suprema Corte, tal proteção da liberdade jornalística não seria aplicável somente aos radifusores e não teria sua força diminuída pela inovação tecnológica trazida pelas televisões a cabo, às quais, assim como as televisões abertas, deveriam ter preservada a discricionariedade quanto à programação que veiculariam.

\section{Os limites para o exercício da autoridade ancilar da FCC em casos julgados pela Corte de Apelações para o Distrito de Colúmbia}

Importantes elucidações sobre os limites para o exercício da autoridade ancilar no direito norte-americano encontram-se nas seguintes decisões da Corte de Apelações para o Distrito de Colúmbia: American Library Association v. FCC $C^{19}$, de 2005, e Comcast Corporation v. Federal Communications Commission ${ }^{20}$, de 2010.

\subsection{O caso American Library Association v. FCC, de 2005}

$\mathrm{O}$ caso tratou de evento relacionado à mudança da televisão analógica para a televisão digital.

Chamada digital television e identificada pela sigla DTV, a televisão digital representou uma significativa evolução tecnológica ao permitir a transmissão de mais informações por um canal do espectro eletromagnético do que seria possível pela televisão analógica. Desse modo, viabilizou-se a transmissão de sinais de vídeo de altíssima qualidade, conhecidos como televisão de alta definição (high definition television) ou de múltiplos e

\footnotetext{
18412 U.S. 94 (1973)

${ }^{19} 403$ F. 3d $689(2005)$

${ }^{20} 600$ F. 3d $642(2010)$
}

Revista de Direito, Estado e Telecomunicações, v. 5, n. 1, p. 195-226 (2013)

DOI: https://doi.org/10.26512/1str.v5i1.21568 
simultâneos conteúdos de vídeo, voz e dados na mesma faixa de frequência tradionalmente usada para uma única transmissão pela televisão analógica.

Segundo normas da FCC e do Congresso a transmissão analógica deveria ser completamente encerrada até o final de 2006.

Com o intuito de prevenir a cópia e redistribuição não autorizada da programação veiculada pela televisão digital, a FCC, em novembro de 2003, editou norma obrigando a que todos os aparelhos receptores de sinais das televisões digitais, fabricados a partir de julho de 2005, reconhecessem um código imiscuído na transmissão e que impediria a redistribuição do conteúdo. O código foi designado broadcast flag, pelo que as referidas normas terem sido nomeadas broadcast flag regulations ou broadcast flag rules ou Flag Order. O código broadcast flag foi concebido para somente afetar os receptores após completada toda a transmissão.

\subsubsection{O litígio}

Entendendo que a tecnologia da televisão digital trazia um risco de massiva redistribuição não autorizada dos sinais das radiodifusoras e assim desestimulá-las na produção de conteúdos de alto valor, a FCC editou a Flag Order com o argumento de ela seria necessária para preservar a viabilidade econômica das televisões abertas (over-the-air television) e não prejudicaria a fruição pelo consumidor dos serviços dessas empresas.

Quando das justificativas para a adoção das broadcast flag regulations, a FCC não se reportou a nenhum dispositivo expresso e fundamentou sua competência para editar as broadcast flag rules apenas na sua competência ancilar decorrente do Title I do Communications Act de 1934. A Comissão, por maioria ${ }^{21}$, entendeu que as normas seriam razoavelmente ancilares à sua competência de garantir a diversidade de conteúdo na programação de televisão e de promover a transição da transmissão analógica para a digital.

Em juízo, a Comissão lembrou que possuía autoridade para promulgar regras que dessem efetividade a seus objetivos legais, ainda que na ausência de dispositivo expresso sobre a específica matéria regulada. Nessa linha, a FCC sustentou sua defesa apenas nos dispositivos do Title $I$ do

\footnotetext{
${ }^{21}$ Dois membros da FCC haviam discordado, alegando que a Flag Order dispunha sobre uso de conteúdo que já estava no campo do domínio público e adentravam à privacidade dos consumidores.
} 
Communications Act de 1934 que lhe conferiam autoridade sobre todas a comunicações por rádio ou fio e que incluíam na definição de comunicação por rádio não apenas a transmissão dos sinais, como também todos os instrumentos, equipamentos e aparatos relacionados com todo o ciclo da emissão e da captação dos sinais, aí incluídos os receptores de televisão digital.

A American Library Association alegou que as broadcast flag rules não tratavam de radiodifusão interestadual conforme definição no Title I do Communications Act de 1934 uma vez que o próprio código (the flag) não era requerido para a transmissão, não tendo sido modificado o modo como se daria a recepção e não surtiria efeitos até que fosse encerrada toda a transferência dos sinais digitais.

A decisão da FCC foi contestada com argumentos no sentido de que: 1) faltaria competência da FCC para impor que aparatos de recepção fossem fabricados com dispositivo para o reconhecimento da broadcast flag; 2) as normas chocar-se-iam com regras do direito de propriedade intelectual; e 3) a medida teria sido arbitrária.

Alegou-se também que a autoridade ancilar não seria ilimitada e que a FCC não poderia regular uma atividade que não caracterizaria comunicação interestadual por rádio ou por cabo e, além disso, que as questionadas regras não tratavam da transmissão de sinais digitais e sim do uso do conteúdo transmitido após completada a sua recepção. Portanto, com esses argumentos, sustentou-se que a FCC teria extrapolado os limites de suas competências expressas ou ancilares.

\subsubsection{A posição da Corte de Apelações}

Lembrando o axioma de que agencias reguladoras (administrative agencies) somente podem regular matérias inseridas nas competências a elas delegadas pelo Congresso, a Corte de Apelações referiu-se a outras decisões da Suprema Corte ${ }^{22}$ que ratificaram o entendimento de que as agências somente podem agir com base em competências expressas sobre, ou no exercício razoável de autoridade ancilar aos seus objetivos legais.

${ }^{22}$ Chevron U.S.A. Inc. v. Natural Resources Defense Council, Inc., 467 U.S. 837 (1984) e United States v. Mead Corp, 533 U.S. 218, 226-27.

Revista de Direito, Estado e Telecomunicações, v. 5, n. 1, p. 195-226 (2013)

DOI: https://doi.org/10.26512/lstr.v5i1.21568 
No entanto, a Corte de Apelações ressaltou que, conforme as decisões da Suprema Corte descritas neste trabalho, o lídimo exercício da autoridade ancilar exigia do ato normativo nela fundamentado o atendimento a duas condições: 1) a matéria regulada deveria enquadrar-se nas competências e objetivos gerais estabelecidos no Title I do Communications Act de 1934; e 2) o conteúdo das normas deveria ser razoavelmente ancilar à efetiva performance das expressas responsabilidades legais da FCC. ${ }^{23}$

Para a Corte de Apelações, as competências e objetivos gerais da FCC definidos no Title I do Communications Act de 1934 alcançariam a regulação de aparelhos de recepção de sinais de televisão, mas somente no tocante à função desses aparelhos no processo de recepção em si.

Destacando que, na definição de comunicação por rádio, aquele estatuto se refereria apenas a instrumentos, equipamentos e aparatos incidentais à transmissão, a Corte de Apelações afirmou que a FCC não poderia dispor sobre o funcionamento desses aparatos após completada a transmissão.

Ela afirmou ainda que a medida adotada pela FCC teria ultrapassado o escopo da autoridade que lhe fora delegada pelo Congresso e, portanto, não teria atendido à primeira condição para o exercício da autoridade ancilar, uma vez que a Flag Order não versava propriamente sobre serviços de comunicação por rádio ou cabo.

Apontou a Corte de Apelações que seu entendimento encontrava respaldo também no conteúdo e na tramitação de outros estatutos sobre telecomunicações, o Channel Receiver Act de 1962 e o Communications Amendments Act de 1982, pelos quais ficou claro que o Congresso nunca conferiu à FCC o poder de regular o uso pelo consumidor dos aparelhos de recepção de televisão após terminada a transmissão dos sinais pelos radiodifusores.

Por fim, concordando com argumentos da American Library Association de que a FCC teria extrapolado os limites de suas competências, a Corte de Apelações anulou as broadcast flag rules.

\footnotetext{
${ }^{23}$ Do original: "The Commission (...) may exercise ancillary jurisdiction only when two conditions are satisfied: (1) the Commission's general jurisdictional grant under Title I covers the regulated subject and (2) the regulations are reasonably ancillary to Commission's effective performance of its statutorily mandated responsibilities".
} 


\subsection{O caso Comcast Corporation v. Federal Communications Commission, de 2010}

Nesse caso tratou-se de decidir sobre ter ou não a FCC autoridade sobre práticas de gerenciamento de rede por parte de provedores de internet via cabo.

Mais especificamente, cuidou-se da competência da Comissão para disciplinar a interferência do provedor sobre o uso da rede pelos consumidores no tráfego de informações peer-to-peer ${ }^{24}$ e que ocupa grandes quantidades da banda.

Em 2005, a FCC publicou suas políticas e princípios sobre a internet em documento conhecido como FCC's Internet Policy Statement, no qual afirmava o direito dos consumidores para a escolha do conteúdo acessado, bem como para rodar aplicações e usufruir de serviços disponíveis na rede (consumers are entitled to access the lawful Internet content of their choice).

Em 2007, descobriu-se que a Comcast interferia no uso que seus assinantes faziam do serviço de internet de alta velocidade para aplicações destinadas à troca de informações peer-to-peer.

Associações de defesa de interesses coletivos apresentaram à FCC reclamação formal contra a prática da Comcast. Em resposta, a empresa argumentou que sua interferência no uso de programas peer-to-peer era necessária ao manejo da limitada capacidade da rede.

Ao final do processo administrativo, em 2008, a FCC manifestou-se por meio de declaração de que a Comcast violara a sua Internet Policy Statement, pois: 1) havia impedido, de maneira significativa, a possibilidade dos consumidores acessarem conteúdos e usarem aplicações de sua escolha; e 2) tinha à sua disposição várias outras opções para gerenciar o tráfego na rede de maneira a não discriminar comunicações peer-to-peer.

Além dessa declaração, a FCC, diante de compromisso da Comcast de adotar novos modos para o gerenciamento da demanda por banda larga, determinou que a empresa lhe apresentasse em detalhes as medidas que adotaria nesse sentido. A Comissão também aventou a possibilidade de

\footnotetext{
${ }^{24}$ Por meio de programas específicos para essa finalidade (peer-to-peer programs), os usuários podem compartilhar grandes arquivos diretamente entre si, sem passar por um servidor central.
}

Revista de Direito, Estado e Telecomunicações, v. 5, n. 1, p. 195-226 (2013)

DOI: https://doi.org/10.26512/lstr.v5i1.21568 
punição caso a Comcast não cumprisse seu compromisso ou não atendesse às determinações de prestar informações.

A Comcast contestou essa ordem da FCC na Corte de Apelações para o Distrito de Colúmbia alegando, entre outras razões, que a Comissão não teria logrado demonstrar sua competência para reger práticas de gerenciamento de rede.

Os argumentos acerca da competência da FCC, dentre os levados a juízo, foram considerados pela Corte de Apelações como os decisivos para o deslinde da causa e neles também reside o interesse para este trabalho.

\subsubsection{O litígio}

As controvérsias se deram sobre princípio, destilado pela Corte de Apelações a partir dos julgados da Suprema Corte já mencionados, e direta e expressamente formulado em anterior decisão dela própria no caso American Library Association v. FCC, de 2005.

Por esse princípio, a validade do exercício da autoridade ancilar depende do atendimento de duas condições (two part test): 1) que a matéria regulada se enquadre nas competências e objetivos gerais estabelecidos no Title I do Communications Act de 1934; e 2) que o conteúdo das normas seja razoavelmente ancilar à efetiva performance das expressas responsabilidades legais da FCC.

Alegou a Comissão que a Suprema Corte, no julgamento do caso National Cable \& Telecommunications Ass' $n$ v. Brand X Internet Services, de 2005, já afirmara a sua competência sobre serviços dos provedores de acesso à internet via cabo. Também afirmou que, na ocasião, ao se pronunciar sobre norma da FCC que definia essa atividade como serviços de informação e não como serviços telecomunicações, afastando a direta incidência das normas do Communications Act de 1934 aplicáveis aos detentores de infraestrutura essencial (Title II - Common carriers) ou às telecomunicações por cabo (Title VI - Cable Communications), a Suprema Corte asseverou que a Comissão permanecia com poderes para impor deveres regulatórios especiais aos provedores de internet, por exemplo, impondo-lhes obrigações de acesso às suas redes, com base na autoridade ancilar decorrente de disposições gerais do Communications Act de 1934 (Title I-General Provisions). 
A FCC buscou arrimo em provisão do Title II que declara ser política dos Estados Unidos promover o desenvolvimento contínuo da internet e de outros serviços computacionais interativos, bem como incentivar $\mathrm{o}$ desenvolvimento de tecnologias que maximizem o controle do usuário sobre quais informações recebe. ${ }^{25}$ Entendeu a Comissão que as ações da Comcast frustravam esse dois objetivos.

A comissão também argumentou que, ao proibir desarrazoada discriminação no acesso à rede, servia ao propósito de sua criação, previsto em dispositivo inserido no Title I, de regular a atividade de telecomunicação interestadual por fio ou rádio, de modo a tornar acessíveis a todo o povo norte-americano serviços de telecomunicações rápidos, eficientes, de alcance nacional e mundial, a preços razoáveis. ${ }^{26}$

A FCC sustentou deter competência para disciplinar as práticas de gerenciamento de redes, pois, embora para isso não tivesse autoridade decorrente de texto expresso, teria autoridade ancilar para regular aquilo que for necessário ao exercício de suas funções, conforme disposição do Communications Act de $1934 .{ }^{27}$

25"It is the policy of the United States-(...) (1) to promote the continued development of the Internet and other interactive computer services and other interactive media;(...) (3) to encourage the development of technologies which maximize user control over what information is received by individuals, families, and schools who use the Internet and other interactive computer services." (47 U.S.C. 230). Texto da versão atual correspondente à Seção 230(b).

26" For the purpose of regulating interstate and foreign commerce in communication by wire and radio so as to make available, so far as possible, to all the people of the United States, without discrimination on the basis of race, color, religion, national origin, or sex, a rapid, efficient, Nationwide, and world-wide wire and radio communication service with adequate facilities at reasonable charges, for the purpose of the national defense, for the purpose of promoting safety of life and property through the use of wire and radio communication, and for the purpose of securing a more effective execution of this policy by centralizing authority heretofore granted by law to several agencies and by granting additional authority with respect to interstate and foreign commerce in wire and radio communication, there is hereby created a commission to be known as the "Federal Communications Commission," which shall be constituted as hereinafter provided, and which shall execute and enforce the provisions of this Act." (47 U.S.C. 151). Texto da versão atual, com modificações em relação à versão original, correspondente à Seção 1.

27"The Commission may perform any and all acts, make such rules and regulations, and issue such orders, not inconsistent with this Act, as may be necessary in the 
Por fim, a FCC alegou que poderia agir para dar efetividade a quaisquer dispositivos do Communications Act de 1934 que declaram a vontade do legislador (legislative will) e que a Suprema Corte teria reconhecido responsabilidade e, em consequência, sua competência ancilar para implementar as várias metas, objetivos e políticas visadas pelo Congresso e expressas no Communications Act de 1934.

A Comcast, em preliminar, qualificou como obter dictum, não integrante do julgamento do mérito da causa, a destacada manifestação da Suprema Corte no caso Brand $X$. Sustentou, que, na ocasião, decidiu-se apenas sobre a licitude do enquadramento dado pela FCC aos provedores de acesso à internet via cabo como serviços de informação, sem afirmar-se que sua autoridade ancilar confere legitimidade a qualquer regra que editar nesse campo.

A Comcast admitiu que, como seus serviços de internet poderiam ser considerados comunicação por fio e, portanto, enquadrados nas disposições gerais do Communications Act de 1934, estaria atendida a primeira condição para o exercício da autoridade ancilar da FFC. No entanto, alegou que a Comissão não havia demonstrado que a ordem questionada atendia o segundo requisito.

Para a Comcast os dispositivos mencionados pela FCC para justificar os seus atos seriam declarações de políticas (statements of policy) e, além de não serem normas de concreta eficácia (operative provisions), não aumentariam nem confeririam poderes à agência, assim não constituindo expressas responsabilidades legais (statutorily mandated responsibilities).

Em sua contestação a FCC ainda acrescentou outros dispositivos que, a seu ver, não seriam declarações políticas e sim textos de expressa delegação de autoridade, e complementariam a fundamentação da sua competência para regular as práticas de gerenciamento de rede por parte dos provedores de acesso a internet por cabo.

O primeiro desses dispositivos, presente no Telecommunications Act de 1996, estabelece que a Comissão deve incentivar o desenvolvimento, em bases razoáveis e tempestivas, de avançados meios de telecomunicações para todos os americanos, utilizando para isso regulação por preço-teto, ou

execution of its functions." (47 U.S.C. 154). Transcrição da versão atual, sem alterações em relação à versão original, correspondente à Seção 4(i). 
suspendendo a exigibilidade de certas regras ou outros métodos de regulação que removam barreiras para o investimento em infraestrutura. ${ }^{28}$

A FCC apresentou também em sua defesa trechos de subseção do Telecommunications Act de 1996, que acrescentou nova seção ao Communications Act de 1934. Esses trechos fixaram que a Comissão: 1) deveria estabelecer procedimentos com vistas à efetiva e eficiente interconexão das redes públicas de telecomunicação ${ }^{29}$; e 2) deveria, no prazo de quinze meses, identificar e eliminar barreiras à entrada de empreendedores e empresas pequenas no ramo de serviços de telecomunicações e de informações e que, esgotado esse prazo, a Comissão deveria encaminhar ao Congresso, a cada três anos, relatório sobre as barreiras ainda porventura existentes. ${ }^{30}$

28"“The Commission and each State commission with regulatory jurisdiction over telecommunications services shall encourage the deployment on a reasonable and timely basis of advanced telecommunications capability to all Americans (including, in particular, elementary and secondary schools and classrooms) by utilizing, in a manner consistent with the public interest, convenience, and necessity, price cap regulation, regulatory forbearance, measures that promote competition in the local telecommunications market, or other regulating methods that remove barriers to infrastructure investment." (Telecommunications Act de 1996, Seção 706(a)).

29"COMMISSION FUNCTIONS- In carrying out the purposes of this section, the Commission - (1) shall establish procedures for Commission oversight of coordinated network planning by telecommunications carriers and other providers of telecommunications service for the effective and efficient interconnection of public telecommunications networks used to provide telecommunications service (...)" (Telecommunications Act de 1996, Seção 256(b)).

30“" (a) ELIMINATION OF BARRIERS- Within 15 months after the date of enactment of the Telecommunications Act of 1996, the Commission shall complete a proceeding for the purpose of identifying and eliminating, by regulations pursuant to its authority under this Act (other than this section), market entry barriers for entrepreneurs and other small businesses in the provision and ownership of telecommunications services and information services, or in the provision of parts or services to providers of telecommunications services and information services. (...) (c) PERIODIC REVIEW- Every 3 years following the completion of the proceeding required by subsection (a), the Commission shall review and report to Congress on - (1) any regulations prescribed to eliminate barriers within its jurisdiction that are identified under subsection (a) and that can be prescribed consistent with the public interest, convenience, and necessity; and (2) the statutory barriers identified under subsection (a) that the Commission recommends be eliminated, consistent with the public interest, convenience, and necessity." (Telecommunications Act de 1996, Seção 257(a)(c)).

Revista de Direito, Estado e Telecomunicações, v. 5, n. 1, p. 195-226 (2013)

DOI: https://doi.org/10.26512/lstr.v5i1.21568 
A Comissão também argumentou haver subsidiariedade entre a regulação das práticas de gerenciamento de rede e a previsão no Title II do Communications Act de 1934 de que os preços cobrados por common carriers devem ser justos e razoáveis. ${ }^{31}$ Acrescentou a Comissão que as práticas da Comcast interrompiam alguns serviços de voz pela internet (voice over Internet Protocol - VoIP) e isso prejudicava o efeito desses serviços sobre os preços da telefonia tradicional, sujeita aos termos do Title II.

Alegou também a FCC que a transmissão de vídeos pela internet afeta a indústria de radiodifusão, com influências sobre geração de programação local, diversidade de opiniões e a atratividade para levar os sinais a determinados mercados. Nesse contexto, a sua ordem à Comcast seria ancilar à sua autoridade para regular os serviços de radiodifusão prevista no Title III.

Por fim, a FCC alegou que a ordem à Comcast estaria relacionada com a sua competência de zelar por preços razoáveis dos serviços das televisões a cabo, pois, na ausência de obstáculos a acessos a vídeos pela internet, o consumidor encontraria uma alternativa ao serviço de vídeo sob demanda oferecido pela televisão a cabo, o que pressionaria para baixo os preços destas.

\subsubsection{A posição da Corte de Apelações}

A Corte de Apelações entendeu que, no caso Brand $X$ a Suprema Corte apenas observara que a FCC poderia impor algumas obrigações especiais aos provedores, sem afirmar uma competência plena da FCC nessa seara. Acrescentou que, nos julgados sobre o exercício da competência ancilar da FCC, a Suprema Corte deixou claro que os atos supostamente calcados nessa autoridade deveriam ser avaliados caso a caso, considerando-se os termos específicos de cada um.

31 "It shall be the duty of every common carrier engaged in interstate or foreign communication by wire or radio to furnish such communication service upon reasonable request therefor (...) All charges, practices, classifications, and regulations for and in connection with such communication service, shall be just and reasonable, and any such charge, practice, classification, or regulation that is unjust or unreasonable is hereby declared to be unlawful (...)" (47 U.S.C. 201). 
No mérito, as análises da Corte de Apelações partiram da classificação das normas do Communications Act de 1934 em duas categorias: 1) as que expressam apenas as políticas gerais do Congresso (statements of policy), e 2) as que expressamente delegam autoridade regulatória à Comissão (statutorily mandated responsibilities).

Segundo a Corte de Apelações, os precedentes da Suprema Corte não teriam afirmado que somente declarações de políticas (statements of policy) constituem expressas responsabilidades legais, e sim que tais responsabilidades decorriam da conjunção dessas declarações de políticas com outras cláusulas que definem expressamente poderes da FCC, tal como a autoridade para regular a radiodifusão conferida no Title III.

Lembrou a Corte de Apelações que, no caso Southwestern, a possibilidade de a FCC restringir o alcance da transmissão de sinais pelas CATV foi relacionada não apenas a declarações de políticas contidas no Title I, mas também à autoridade expressamente delegada, no Title III, para a Comissão definir áreas de atuação dos radiodifusores a fim de evitar interferências entre as várias estações e proporcionar equitativa distribuição dos serviços entre os vários estados e comunidades.

Sobre o caso Midwest de 1972, anotou a Corte de Apelações que a exigência para que as CATVs gerassem programação própria foi relacionada à autoridade regulatória sobre a radiodifusão expressamente conferida à FCC no Title III para a promoção, dentre outros objetivos, do fortalecimento da programação local e da diversificação de programas e tipos de serviço.

A Corte de Apelações destacou que, no caso Midwest de 1979, foi rejeitado argumento de que a FCC poderia atuar apenas com base nos objetivos gerais inscritos na lei. Lembrou que, nesse caso, a principal razão de decidir residira na expressa vedação contida no Communications Act de 1934 de imposição aos radiodifusores de regras apropriadas a common carriers e que, dada a natureza acessória da autoridade ancilar, tal proibição alcançava também as televisões a cabo. Reforçou que, não obstante o reconhecimento de uma ampla autoridade ter sido conferida à FCC, foi ressaltado que esse poder não era ilimitado e deveria estar contido nas fronteiras dadas por dispositivos legais que tratam diretamente da radiodifusão. 
Para a Corte de Apelações, a compreensão de que as declarações de políticas não sustentam por si sós o exercício da autoridade ancilar da FCC decorre do axioma de que as agências reguladoras devem agir somente com a autoridade a elas delegada pelo Congresso. Enfatizou, então, que declarações de políticas são apenas isso, declarações de política, e não constituem delegação de autoridade regulatória.

No entanto, a Corte de Apelações prosseguiu afirmando que as declarações de políticas ajudam a delinear os contornos da autoridade regulatória emanada de específicos e diretos dispositivos de delegação de competências. Assim, a FCC, deve ter em mente a política, declarada no Title I, de promover serviços de comunicação de alcance nacional a preços razoáveis ao exercer autoridade expressamente prevista no Title II (e.g., de fixar tarifas razoáveis para serviços telefônicos), no Title III (e.g., de conceder licenças de radiodifusão de acordo com o interesse do público) ou no Title VI (e.g., de impedir meios desleais de competição entre os operadores de cabos que limitem o acesso do consumidor a certos tipos de programas). Defendeu que é nesse sentido que deveria ser compreendida a previsão, também no Title I, de que a Comissão tem competência para regular aquilo que for necessário ao exercício de suas funções.

Ou seja, para a Corte de Apelações, embora as declarações de políticas inseridas no Title I possam ajudar a compreender a extensão da autoridade da FCC, essa autoridade será sempre ancilar aos poderes diretamente conferidos nos Títulos II, III ou VI.

A Corte Apelações ainda ressaltou que, no caso em exame, a FCC, ao reportar-se aos artigos do Communications Act de 1934 que se referem aos propósitos gerais de sua criação ou de ser uma política do país a maximização do controle do usuário sobre as informações que recebe pela internet $^{32}$, não evoca tais dispositivos como instrumentos para lançar luz sobre nenhuma de suas competências expressamente delegadas em dispositivos do Title II, III ou VI ou em qualquer outro texto normativo. Mais claramente, destacou a Corte de Apelações, a FCC não se referiu às ditas declarações de políticas para argumentar que sua ordem à Comcast

\footnotetext{
${ }^{32}$ Embora o dispositivo a isso alusivo esteja no Title II, seu conteúdo é de uma declaração de política, o que inclusive indica o título da subseção no qual está inserido.
} 
acerca do gerenciamento do tráfego na internet, embora recaia em área sobre a qual não possui autoridade regulatória expressa, é necessária para a efetiva regulação de áreas para a quais possui competência direta, como, por exemplo, dos serviços de comunicação por cabo disciplinados no Title VI. A Corte considerou, portanto, insuficiente a argumentação apresentada pela FCC quanto a esse tópico.

Em seguida, a Corte de Apelações debruçou-se sobre as demais normas acrescentadas pela FCC em sua contestação sob a alegação de que não seriam declarações de políticas e sim delegações expressas de competências.

Quanto ao dispositivo que impele a FCC a incentivar o desenvolvimento de avançados meios de telecomunicações para todos os americanos, embora reconhecendo que nele há comando direto à Comissão, a Corte de Apelações lembrou que em outro e ainda vigente ato, a agência manifestou entendimento de que tal artigo não constituiria uma delegação de competência direta e independente. Assim, como a FCC não questionou ou modificou expressamente esse entendimento e dado o princípio de que as agências não podem abandonar suas posições anteriores sem a devida motivação, o argumento recai na mesma objeção de que a autoridade ancilar não pode ser fundamentada apenas em declarações de políticas.

A Corte de Apelações refutou o argumento de que uma autoridade da FCC sobre matéria não diretamente disciplinada no Communications Act de 1934 decorreria do artigo do Telecommunications Act de 1996 acerca do papel da FCC na promoção da efetiva e eficiente interconexão das redes de telecomunicação, vez que, na mesma seção, há texto claro no sentido de que nenhuma expansão ou redução de competência ali se estabelecia. ${ }^{33}$

Sobre o dever de a Comissão encaminhar relatório ao Congresso sobre barreiras à entrada nos mercados de serviços de telecomunicações e de informações, a Corte de Apelações admitiu nisso poder-se ver uma competência da agência para impor obrigações de transparência sobre as

33"COMMISSION'S AUTHORITY- Nothing in this section shall be construed as expanding or limiting any authority that the Commission may have under law in effect before the date of enactment of the Telecommunications Act of 1996." (Communications Act de 1934, Seção 629(f), acrescentada pelo Telecommunications Act de 1996).

Revista de Direito, Estado e Telecomunicações, v. 5, n. 1, p. 195-226 (2013)

DOI: https://doi.org/10.26512/lstr.v5i1.21568 
entidades reguladas, mas não para exigir um modo de operação em atividade não diretamente sujeita à autoridade da FCC.

Quanto ao comando do Title II sobre deverem os common carriers cobrar preços justos e razoáveis, a Corte de Apelações não viu, no modo como a FCC argumentou sobre isso em sua contestação, a devida fundamentação para exercício da autoridade ancilar. A Corte anotou ainda que, embora na motivação de sua ordem à Comcast, a FCC tivesse indicado como o bloqueio de tráfego pela Comcast poderia direcionar a demanda por acesso à rede para outros provedores que operam em regime de common carrier, aumentando-lhes os custos variáveis, a Comissão não apresentou esse argumento em sua contestação, o que deveria ser interpretado como uma renúncia a essa tese. Sobre os efeitos do gerenciamento de rede relativos aos serviços de VoIP, a Corte de Apelação lembrou que, por não ter sido oportunamente apresentado como motivação para a ordem à Comcast, esse argumento não servia à defesa em juízo.

Na mesma linha, a Corte de Apelações rejeitou os argumentos da FCC sobre a relação entre a sua ordem à Comcast e sua autoridade sobre a radiodifusão, contemplada no Title III. Lembrou que não havia na motivação da ordem à Comcast nenhuma referência entre sua decisão e dispositivos do Title III e que não vislumbrava como poderia ser demonstrada a alegada relação entre a transmissão de vídeos pela internet e a indústria de radiodifusão.

Para a Corte de Apelações o argumento da FCC sobre a relação entre a ordem à Comcast e regulação de preços do serviço de vídeo sob demanda oferecido pelas televisões a cabo não poderia prosperar porque, por disposição expressa no próprio Title VI, é vedado à Comissão regular os preços de serviços dessa natureza.

Concluiu, então, a Corte de Apelações, que a FCC não logrou demonstrar o vínculo entre sua alegada autoridade para regular os serviços de internet oferecidos pela Comcast e qualquer de suas responsabilidades expressamente e estatutariamente fixadas. 


\section{Reconhecimento no Direito Brasileiro de poderes implícitos às responsabilidades legais da Administração Pública}

Os já descritos casos apreciados pela Suprema Corte norte-americana e pela Corte de Apelações para o Distrito de Colúmbia apresentam suficientes elementos para que sejam indicados pontos de convergência entre a jurisprudência e a doutrina brasileiras no campo do direito administrativo e a teoria da autoridade ancilar construída pela Suprema Corte norteamericana.

É de ampla aceitação na doutrina brasileira que o escopo e a extensão de competências administrativas são dados pelas finalidades públicas que deve perseguir a Administração Pública. Assim, toda a organização, os poderes e a atuação das entidades e dos órgãos estatais devem ser compreendidos como uma função do interesse público que lhes guia. Nessa linha, conforme já esclareceu BANDEIRA de MELLO (2010, p. 99) ${ }^{34}$ :

Na idéia de função o dever é que é predominante, visto que o poder a ele ligado sempre cumpre papel instrumental, ancilar, percebe-se também que os "poderes" administrativos, em cada caso, não têm por que comparecer além da medida necessária para o suprimento da finalidade que 0 justifica.

Portanto, em se tratando de competências expressas, é sabido que essas são condicionadas pelas responsabilidades e finalidades atribuídas e postas à Administração Pública. Nesses limites, poderes administrativos implícitos, não expressos, podem ser legitimados por seu caráter necessário e ancilar ao cumprimento de missões definidas em lei. Sobre isso escreveu BANDEIRA de MELLO (2010, p. 99) ${ }^{35}$, para afirmar a validade do princípio da proporcionalidade sobre a ação administrativa, não por previsão direta mas subjacente aos arts. $5^{\circ}$, II, 37 e 84, IV, da vigente Constituição brasileira:

0 fato de se ter de buscá-lo [o respaldo constitucional do princípio da proporcionalidade] pela trilha assinalada [arts. $5^{\circ}$, II, 37 e 84, IV da CF/88] não o faz menos amparado, nem menos certo ou verdadeiro, pois tudo aquilo que se encontra implicado em um princípio é tão certo e

${ }^{34}$ BANDEIRA DE MELLO, Celso Antônio Bandeira de. Curso de direito administrativo. 27. ed. rev. e atual. São Paulo : Malheiros, 2010. p. 99 ${ }^{35}$ Op. cit., p. 112

Revista de Direito, Estado e Telecomunicações, v. 5, n. 1, p. 195-226 (2013)

DOI: https://doi.org/10.26512/lstr.v5i1.21568 
verdadeiro quanto ele. Disse Black ${ }^{36}$ que tanto faz parte da lei o que nela se encontra explícito quanto o que nela implicitamente se contém.

Na jurisprudência brasileira, referências a tais poderes implícitos podem ser encontradas nas decisões do Supremo Tribunal Federal (STF) no Mandado de Segurança 26.547 e no Recurso Extraordinário 603.583.

No julgamento do MS 26.547, o STF reconheceu competência do TCU para adotar medidas cautelares, mesmo sem oitiva da parte prejudicada. $\mathrm{Na}$ ocasião, o Relator, Ministro Celso De Mello, anotou:

Com efeito, impende reconhecer, desde logo, que assiste, ao Tribunal de Contas, poder geral de cautela. Trata-se de prerrogativa institucional que decorre, por implicitude, das atribuições que a Constituição expressamente outorgou à Corte de Contas.

Entendo, por isso mesmo, que o poder cautelar também compõe a esfera de atribuições institucionais do Tribunal de Contas, pois se acha instrumentalmente vocacionado a tornar efetivo o exercício, por essa Alta Corte, das múltiplas e relevantes competências que lhe foram diretamente outorgadas pelo próprio texto da Constituição da República.

Isso significa que a atribuição de poderes explícitos ao Tribunal de Contas, tais como enunciados no art. 71 da Lei Fundamental da República, supõe que se reconheça, a essa Corte, ainda que por implicitude, a possibilidade de conceder provimentos cautelares vocacionados a conferir real efetividade às suas deliberações finais, permitindo, assim, que se neutralizem situações de lesividade, atual ou iminente, ao erário.

Impende considerar, no ponto, em ordem a legitimar esse entendimento, a formulação que se fez em torno dos poderes implícitos, cuja doutrina - construída pela Suprema Corte dos Estados Unidos da América no célebre caso McCULLOCH v. MARYLAND (1819) enfatiza que a outorga de competência expressa a determinado órgão estatal importa em deferimento implícito, a esse mesmo órgão, dos meios necessários à integral realização dos fins que lhe foram atribuídos.

${ }^{36}$ BLACK, Henry Campbell. Handbook on Construction and Interpretation of Law. St. Paul, Minn., West Publishing Co. 1986, p. 62: "It is a rule of construction that wich is implied in a statute is as much a part of it as what is expressed". 
Na realidade, o exercício do poder de cautela, pelo Tribunal de Contas, destina-se a garantir a própria utilidade da deliberação final a ser por ele tomada, em ordem a impedir que o eventual retardamento na apreciação do mérito da questão suscitada culmine por afetar, comprometer e frustrar o resultado definitivo do exame da controvérsia.

Torna-se essencial reconhecer - especialmente em função do próprio modelo brasileiro de fiscalização financeira e orçamentária, e considerada, ainda, a doutrina dos poderes implícitos (MARCELO CAETANO, "Direito Constitucional", vol. II/12-13, item n. 9, 1978, Forense; CASTRO NUNES, "Teoria e Prática do Poder Judiciário", p. 641/650, 1943, Forense; RUI BARBOSA, "Comentários à Constituição Federal Brasileira", vol. I/203-225, coligidos e ordenados por Homero Pires, 1932, Saraiva, v.g.) - que a tutela cautelar apresentase como instrumento processual necessário e compatível com o sistema de controle externo, em cuja concretização o Tribunal de Contas desempenha, como protagonista autônomo, um dos mais relevantes papéis constitucionais deferidos aos órgãos e às instituições estatais

No RE 603.583, tratou-se da constitucionalidade da exigência de aprovação em exame organizado pela $\mathrm{OAB}$ para o exercício da profissão de advogado. O Ministro Ricardo Lewandowski frisou a necessária ligação entre a realização do exame pela $\mathrm{OAB}$ e as responsabilidades que the atribuiu o Estatuto da Advocacia, nos seguintes termos:

Eu queria rememorar uma teoria bastante interessante e já clássica, a Teoria dos Poderes Implícitos. Essa Teoria foi desenvolvida pela Suprema Corte dos Estados Unidos nos longínquos idos de 1819. 0 Ministro Celso de Mello, certamente, lembra-se bem do caso McCulloch v. Maryland. Tratava-se de uma discussão dos poderes dos Estados que não estavam explicitados na Constituição. Então, desenvolveu-se essa Teoria, segundo a qual, quando se confere a um determinado órgão estatal certas competências, implicitamente se delega a esses mesmos órgãos os meios para executá-las.

O que acontece, no caso, em brevíssimo resumo - os Colegas já levantaram os pontos principais, e a Ministra Cármen Lúcia acabou de tocar num ponto que me parece fulcral: a União, com base na competência que lhe outorga a Constituição, no artigo 22, inciso XVI, ao regular o exercício da profissão de advogados, permitiu que o Conselho Federal da Ordem dos Advogados o fizesse mediante provimento, 
exatamente para atender às situações cambiantes de cada momento histórico que essa Corporação enfrenta. Por que isso? Exatamente porque no artigo 44 - que a Ministra Cármen Lúcia trouxe à colação -, no inciso I, assinala-se que compete à $\mathrm{OAB}$ promover com exclusividade, dentre outros fins, a seleção e a disciplina dos advogados na República Federativa do Brasil. Ou seja, atribuiu-se à Corporação dos Advogados determinadas obrigações, determinadas atribuições e certas competências. Evidentemente, quando o legislador atribui a esse órgão, que é um órgão estatal ou de colaboração com o Estado, determinadas atribuições, é preciso compreender que implicitamente também lhe outorgou os meios. E os meios são exatamente estes: são as provas que se fazem periodicamente, provas essas - diga-se - absolutamente objetivas e impessoais, elaboradas por profissionais isentos e especializados nos respectivos ramos de Direito.

Então, a mim me parece que essa é uma Teoria que saiu do âmbito do Direito Constitucional e já constitui um princípio geral de Direito.

\section{Conclusão}

Em suma, a comparação dos institutos da autoridade ancilar e dos poderes implícitos esboça o desenvolvimento de teoria que poderá viabilizar o reconhecimento de competências administrativas das agências reguladoras brasileiras que, embora não estejam dispostas expressamente, emergem como uma imperiosidade para o cumprimento de responsabilidades diretamente dadas por lei, segundo contornos definidos na mesma legislação de regência. Trata-se, portanto, da devida tradução de institutos jurídicos para enriquecimento argumentativo da tradição administrativa de vínculo funcional de competências para o fim de devida explicação interpretativa dos limites de poderes não expressamente enunciados nos documentos legais autorizadores de atuação regulatória em geral, e do setor de telecomunicações em especial.

\section{Julgados analisados}

American Library Association v. FCC 403 F. 3d 689 (2005).

Comcast Corporation v. Federal Communications Commission 600 F. 3d 642 (2010). 
Federal Communications Commission v. Midwest Video Corp. 440 U.S. 589 (1979).

Supremo Tribunal Federal do Brasil. Mandado de Segurança $\mathrm{n}^{\circ}$ 26.547, j. 6/6/2007, Dje de 25/09/2009.

Supremo Tribunal Federal do Brasil. Recurso Extraordinário no 603.583, j. 26/10/2011, Dje de 25/05/2012.

United States v. Southwestern Cable Co. 392 U.S. 157 (1968).

United States v. Midwest Video Corp. 406 U.S. 649 (1972). 